\title{
The Role of Effective Discharge Planning in Preventing Homelessness
}

\author{
Thomas E. Backer · Elizabeth A. Howard · Garrett E. Moran
}

Published online: 1 June 2007

(C) Springer Science+Business Media, LLC 2007

\begin{abstract}
Effective discharge planning can contribute significantly to preventing homelessness. As part of a larger continuum of care, this process can help people reach goals of stable housing, recovery, and increased quality of life in the community. Discharge planning identifies and organizes services a person with mental illness, substance abuse, and other vulnerabilities needs when leaving an institutional or custodial setting and returning to the community. A three-component model is presented, relating discharge planning to institutional assessment and treatment, and to community services. Service challenges, innovative programs (based on a state-by-state analysis), and recommendations for enhancing discharge planning also are discussed.
\end{abstract}

Keywords Preventing homelessness - Discharge planning - Continuum of care · Cooccurring disorders · Coordination of services

"The lack of discharge planning is one of the major sources of increased costs, especially for people with mental illnesses who find themselves homeless."

-Bill Compton, mental health consumer and director of Project Return in Los Angeles

"'In our facility, we pride ourselves on having good discharge planning, and it includes planning for things people could do to take care of themselves." -Dr. Tim Kuehnel, mental health administrator in Camarillo, California

T. E. Backer $(\bowtie) \cdot$ E. A. Howard

Human Interaction Research Institute, 5435 Balboa Boulevard, Suite 115, Encino, CA 91316, USA

e-mail: hirila@aol.com

G. E. Moran

Westat, 1650 Research Boulevard, Rockville, MD 20850-3129, USA 
Services and resources for preventing homelessness in communities often do not fit together very well. Like parts of a giant puzzle, they work best if coordinated into a "continuum of care." Fully integrated services are the ideal, so that people using them can do "one-stop shopping" without having to deal with multiple agencies. Some communities now have such a strategy in place, but often certain services or resources still are fragmented or missing from the continuum. When they are, the risk of homelessness increases.

One part of the puzzle is discharge planning - a process for identifying and organizing the services and connections a person with mental illness, substance abuse, and other vulnerabilities will need when leaving an institutional or custodial setting and returning to the community. Whether done informally or in a written plan, and whether done by the person's counselor, a discharge planner, or an entire team, discharge planning can help consumers (the term used here for people also called "patients," "clients", or "inmates", depending upon the facility) reach goals of stable housing, recovery, self-sufficiency, and increased quality of life. In its review of the causes of homelessness, the Interagency Council on Homelessness (1994) identified inadequate discharge planning as a significant factor contributing to homelessness among persons with mental illness and/or substance use disorders. People discharged from institutional settings, particularly psychiatric hospitals, to urban areas have a high incidence of homelessness (Belcher 1991; Burns et al. 2003). There often are difficult-to-cross boundaries between treatment or custodial facilities (and personnel working in them), and community resources. Discharge planning can "span the boundary", between the two, helping establish contacts and promoting information sharing.

For people at risk for homelessness, the continuum of care begins with outreach and assessment, and leads to stable housing supported by needed services (this model could fit with a 'Housing First', approach, too, by placing housing early in the continuum). In the continuum of care model, community-based treatment, independent living skill development, employment development, education, securing of benefits and entitlements, and other services all are linked through referrals and networking (Kiser et al. 1999). However, it is important to emphasize that discharge planning will have little impact unless housing and other services and community resources, are actually available. Also, financial resources must be available to support the costs of discharge planning itself as a part of the overall service process. Just planning for it or mandating it is not enough. At the same time, although the initial cost of discharge planning programs for people at risk for homelessness may be high, system-wide savings may eventually offset these costs.

The term "discharge planning" itself has to be defined carefully. The American Academy of Community Psychiatrists (AACP) and others recently have come to prefer the term "transition planning," arguing that it better captures the larger concept of continuing care (AACP 2001). Here, however, "discharge planning"' is used to mean planning for a person's exit from a treatment, correctional, or other custodial setting into the community and into a residential setting. Transition planning as used here refers to moving from one level of service to another (e.g., from a correctional facility to a state hospital, or from a maximum to a minimum security facility), including transition into a facility. In the discussion that follows, 
this definition of discharge planning (still the most widely used one today in both the service and research literature) is placed in the larger context of a three-component "boundary-spanning"' model, followed by identification of challenges, recent innovations in practice (including a state-by-state analysis), and needed next steps in enhancing discharge planning as a "part of the puzzle" for addressing prevention of homelessness.

\section{Background}

Discharge planning procedures were first developed by general hospitals (Kadushin and Kulys 1993), and are required by the Joint Commission on Accreditation of Health Care Organizations for both hospitals and behavioral health organizations (JCAHO 2003). The literature on discharge planning and homelessness includes various explorations about the transition to outpatient services and its impact on subsequent hospitalizations (Caton 1981; Fernando et al. 1990; Hogarty 1972; Lurie et al. 1981; Rock 1987). Clinical experience shows that lack of proper planning increases the chance that people will return to jails or mental health facilities, or relapse into problem behaviors (Community Shelter Board 2002). The few studies that have examined outcomes of discharge planning quantitatively have mixed results. Sosin and Grossman (1991) found that discharge planning did not make a difference between consumers who later were housed versus those who became homeless. Moran et al. (2005) conducted a comprehensive literature review and analysis, concluding that only a modest amount of research evidence presently supports the effectiveness of discharge planning, and that intensive empirical research would not be cost-effective at this time for various technical reasons.

However, good discharge planning practices have been defined from recent studies in the fields of homelessness (AACP 2001; Mangano and Hombs 2002), mental health (SAMHSA 1997) and criminal justice (Osher et al. 2002). The positive research evidence that does exist suggests that success in consumers' efforts to find stable housing can result from good discharge planning (SAMHSA 1997, 2003). Good discharge planning weaves together people and agencies who provide services for stable and permanent housing, integrated with ongoing psychiatric and psychosocial treatment/rehabilitation, as well as community services (e.g., transportation, money management, medication management, etc.) to support independent living. At present, a push for discharge planning in service environments represents a blend of common sense, clinical experience, and a very modest amount of empirical evidence. The specific good practices emerging from this recent work are presented in the next section.

Many shortcomings in discharge planning practice also exist. According to one recent estimate, only a third of justice system inmates with mental illnesses nationally receive discharge planning services (Bazelon Center for Mental Health Law 2004). Staff in jails and prisons are often unaware of approaches to good discharge planning (e.g., pre-release agreements with the Social Security Administration). Gantt et al. (1999) explored how lack of housing and community treatment impeded good discharge planning in mental hospitals, finding that such 
impediments significantly increased the likelihood of consumers returning to the hospital within 90 days.

Some positive changes are occurring. The U.S. Department of Housing and Urban Development (HUD) published a resource bibliography on discharge planning (2003), and requires that applicants for HUD Continuum of Care grants certify that they will use discharge planning to prevent "discharge to homelessness" (Form HUD-40076-C2-CIECH 02/2003). States, counties, and cities have increased their attention to discharge planning, often driven by financial and legal factors. For example, following a class action lawsuit, on January 8, 2003, New York City agreed to provide discharge planning services for inmates with serious mental illnesses (Burley 2003).

\section{A Way to Think about Discharge Planning}

Discharge planning takes many forms, from a few minutes spent informally with a consumer, to a comprehensive process that involves the use of a standardized instrument. In all these forms, discharge planning can be thought of as part of a continuum of care, starting with assessment and treatment, and ending with services and service coordination back in the community. Discharge planning is a "boundary spanner' between these two ends of the continuum, connecting institutional and community services based on assessment of what a consumer needs. The following elements are involved in the continuum of care, and are discussed further in Table 1.

\section{Assessment/Treatment}

Assessment ideally begins at the time of intake, includes attention to a number of consumer strengths, weaknesses, and need for services (see Table 1) and continues throughout the period of residency (Christ et al. 1994; Commonwealth of Massachusetts 2002; Florida Department of Children and Families 2006). For initial assessment, the use of symptom checklists and screening instruments can be helpful, and their results will have impact on later discharge planning. The time for assessment and discharge planning depends upon how long the individual is likely to spend in the facility. For example, "fast-track" strategies are required for inmates and consumers spending less than 72 hours (Osher et al. 2002).

Assessment should be based on the assumption that consumers at risk for homelessness are likely to have multiple problems (AACP 2001; Minkoff 2001). The most common cooccurring disorders are mental illness and substance abuse. However, people who have mental illnesses frequently have other disorders, such as HIV/AIDS or trauma-related symptoms. Many also have cognitive impairments (Backer and Howard, in press), some arising from developmental disabilities and head injuries.

If initial screening reveals a history of homelessness or residential instability, discharge planning should focus on housing interventions (e.g., negotiating to retain the person's prior housing, locating new housing, considering supportive housing). It is also important to determine economic status, and whether the individual is 
Table 1 Elements of continuum of care

\begin{tabular}{|c|c|c|}
\hline $\begin{array}{l}\text { Assessment/treatment in treatment/ } \\
\text { custodial institution }\end{array}$ & Discharge planning & $\begin{array}{l}\text { Services \& services coordination } \\
\text { in community }\end{array}$ \\
\hline Mental health status & Client involvement & Housing with supports \\
\hline Substance abuse status & Family involvement & Mental health services \\
\hline HIV status & $\begin{array}{l}\text { Planning coordinator or team } \\
\quad \text { (if available) }\end{array}$ & Substance abuse services \\
\hline Trauma status & Staff input & Income support/benefits \\
\hline Physical health status & Written discharge plan & Food \& clothing \\
\hline Cognitive impairments & $\begin{array}{l}\text { Handling costs of discharge } \\
\text { planning }\end{array}$ & Transportation \\
\hline Residential stability—past/future & & Legal/civic services \\
\hline Income/benefits status & & Employment opportunities \\
\hline Employment history/potential & & $\begin{array}{l}\text { Case management/services } \\
\text { integration }\end{array}$ \\
\hline \multirow[t]{3}{*}{ Social supports } & & Advocacy \\
\hline & & $\begin{array}{l}\text { Crisis intervention (relapse } \\
\text { Prevention }\end{array}$ \\
\hline & & Eviction prevention \\
\hline
\end{tabular}

employable, or, if not, eligible for entitlements. In some states, it is possible to apply for entitlements like Medicaid, Social Security, Veteran's benefits, food stamps or welfare while the person is still in residency or custody (Osher et al. 2002).

\section{Discharge Planning}

Discharge planning may vary widely in its extent and formality, depending on a consumer's needs and resources available to support this process. It typically results in some sort of written plan, and often is performed by one individual, typically a case manager or the clinician working most closely with the consumer. Ideally, discharge planning is performed by a planning team that includes the consumer, family members when appropriate, a community caseworker, resource specialists and representatives from community service providers. Discharge planning needs to be culturally and linguistically sensitive to the beliefs and communication styles of each individual, as well as to their needs and preferences (AACP 2001; Western Interstate Commission for Higher Education; WICHE Mental Health Program 1998).

Discharge planners should already have in place partnerships with local community providers, as well as agreements with housing providers. This is not easy. Landlords may be reluctant to accept tenants with histories of mental illness, substance abuse, or violence. Those with convictions for certain offenses (i.e., sex offenses, arson, burglary) are particularly difficult to place. This reality mandates determining housing options long before the discharge planning process begins (Osher et al. 2002). If the person is being discharged to a community remote from the institutional setting, contacts with that community also are essential. The 
consumer also needs to be consulted to determine what housing options are acceptable, and to work through concerns with the individual and family.

In addition, discharge planning needs to include options for providing medication and medication management, food and clothing, transportation, behavioral health services, medical care and in-home supports (money management, nutrition guidance). Planning for these services will be facilitated by compiling a compendium of available community resources, as well as by agreements that are already in place before discharge planning actually begins. Another important part of planning is assessing the person's financial status and determining whether services are affordable. If not already done at the assessment stage, this may include applying for benefits with help from case managers (Rosen and Perret 2005).

Innovative approaches to support the discharge planning process around housing include a centralized database of housing for special needs populations used by case managers in Phoenix, Arizona, with online applications and updated notices of vacancy. Inmates in Hawaii who are eligible for parole are released on furlough for short periods so they can tour potential housing sites. In New York State, videoconferencing is used so that housing providers can interview applicants when housing is outside the local area of the prison or state hospital (Wells 2005, Principles of Effective Transition Planning. Unpublished paper).

\section{Services/Services Coordination \& Integration}

To implement a plan effectively, community service providers must work with the individual and his/her family in a coordinated fashion. Clear communication about the timing and delivery of services is key, along with ongoing case management, which often falls to a community agency to which the person has been referred.

In Texas, the corrections system refers a prison inmate with mental health treatment needs and a pending release date to the regional mental health services and benefits coordination office in the county where the inmate is expected to live. These offices then send workers to meet with the inmate and participate in the discharge planning process. Upon release, the workers from the inmate's new county of residence serve as coordinators for the provision of services (Bazelon Center 2006). Such coordination may become part of a "wraparound" model of services that may lead to greater service integration. For instance, the Assertive Community Treatment (ACT) team model (Lehman et al. 1999) provides a supportive infrastructure for implementing a good discharge plan, because it offers a single point of contact, flexible services, and much individualized attention.

In an ideal system, service programs are integrated through collaborations, joint ventures, and memoranda of agreement to provide a single point of accountability and service provision from a single location. The idea of service integration is not new. HHS's Office of Human Development Services promoted this concept in the 1980s (Backer and Howard 1997). A growing number of dual diagnosis service programs integrate drug abuse and mental health services, and many state and local systems are building the concept of services integration into their 10-year plans to end chronic homelessness. Integrated services ensure "one stop shopping' that goes beyond services coordination. 
In either service coordination or service integration, services may take different forms in different communities. For instance, housing need not be independent living in a single-occupancy apartment or house, but it does need to be stable. In some cases, supportive housing with services that address health, mental health, and employment issues also may be provided. A "Housing First" model also is emphasized in some service systems, such as the Pathways to Housing project in New York City, which enables people with multiple disabilities to go directly from shelters into permanent housing in apartments that are privately owned (Wells and Lezak 2004).

\section{Challenges of Discharge Planning}

Among the challenges to effective discharge planning are the following:

(1) There often is a lack of time to do discharge planning, especially during a short hospital or jail stay. In such cases, a creatively abbreviated process may be needed, focusing on the most urgent needs identified in an initial assessment.

(2) In too many cases, no one in the treatment or custodial facility is directly accountable for the quality or success of a discharge plan. Several service workers may contribute at least informally to discharge planning, but not in a coordinated way with one person who is accountable. Ideally, what is needed is a team process with clear accountability for outcomes, and backup for each area of responsibility, so that the job gets done even if one or more individuals involved in the complex process drop out. When this is not feasible, facility personnel may need to create a strategy for ensuring accountability, even if it is informal.

(3) Financing of discharge planning is a challenge because there is no separate payment mechanism in most systems. Eligibility and funding sources often dictate whether discharge planning can happen for a particular consumer, despite evidence that the outcomes from good discharge planning can reduce the cost of public services (Culhane et al. 2002). Because discharge planning often does not have a single, formal "home" in either public or private service systems, using "billable hours" for it may be problematic. Sometimes, however, this "murkiness" of definition may work to the advantage of those who see the value of discharge planning who then can find ways to fund it creatively!

Another challenge relative to financing is that in Medicaid and managed care systems the length of time permitted in a psychiatric facility may be too short to permit full stabilization of the patient. In these cases, discharge planners are asked to discharge to shelters or transitional housing people whose symptoms may be too severe to allow for community re-integration and permanent housing.

(4) There is a general lack of consensus on standard practice for effective discharge planning systems. Few programs have written protocols to 
standardize discharge planning by staff, and few use screening instruments, even though some are available and have shown promise (Christ et al. 1994). There are good practices from innovative discharge planning projects, as already discussed, but because there is only limited empirical research about discharge planning, none of these innovations have been formally identified as evidence-based practices (EBPs).

However, some guidelines and written protocols developed by these innovative projects have been documented and are available on the Internet and from their developers. For example, the Massachusetts Housing and Shelter Alliance has compiled a set of practice models that can be replicated in many communities (available at www.nhchc.org/dischargeplanning.shtml). Other resources for good practices include AACP (2001) and Osher et al. (2002).

(5) Adequate training is unavailable for mental health and homeless service workers about the tools and techniques of discharge planning. Although most people working in homeless services or mental health service systems understand the concept, specific training in how to do good discharge planning, and how to integrate it into the overall system, is lacking at present. In systems where training is lacking the written resources just mentioned may be valuable.

(6) The discharge planning process needs to be tailored to differing community characteristics. For example, on one hand, rural communities with few resources may be limited in the choices they can offer to the person being discharged. Small treatment or custodial facilities may not have the resources to assemble a discharge planning team, and the process may be informal and fragmented. On the other hand, rural communities may have an advantage in being able to build strong collaborative relationships among the few providers of housing and services in the area.

(7) Many consumers will experience relapse, and will need to return to an institutional treatment setting. Negative emotional states, interpersonal conflict, and social pressure all increase the likelihood of relapse (Parks and Marlatt 2000). Discharge plans thus need to include attention to relapse prevention.

(8) Eviction prevention also needs to be part of discharge planning because waiting until the problem emerges after discharge can be too late for effective intervention. Such programs have been included in some local 10-year plans to end chronic homelessness (Lamport 2005). For example, in Berkeley, California, a cash-based eviction prevention program provides short-term rental assistance, rental guarantee and move-in costs for homeless and low income individuals and households (City of Berkeley 1996).

(9) People who are homeless and have multiple vulnerabilities often experience stigma and discrimination when trying to access services from different agencies. Attention to this reality also needs to be part of good discharge planning, so that strategies for coping with it can be developed. 


\section{Innovations in Discharge Planning}

A state-by-state analysis of state and territorial 10-Year Plans to End Chronic Homelessness showed that in nearly every state, discharge planning is viewed as an effective prevention strategy and is included, or at least mentioned, in the state's plan. Housing is at the center of most 10-year plans, but discharge planning and other supportive services (such as relapse and eviction prevention) also are seen as necessary components. Discharge planning innovations identified include the following, chosen from representative states.

In Colorado, efforts to improve the resources needed by discharge planners are being made in the state's justice, mental health, child welfare, and public health systems. Training and technical assistance (e.g., accessing benefits and entitlements) are offered to homeless providers, corrections personnel, and child welfare and mental health centers to prevent or severely limit these institutions from discharging people to shelters. Also, Partnership for Active Community Engagement (PACE) projects in six Colorado communities promote discharge planning for offenders with serious mental illnesses (Colorado Department of Human Services 2006).

In Florida, an important part of discharge planning for inmates of the Department of Corrections is an agreement with the Social Security Administration permitting medical staff at correctional facilities to assist inmates in applying for benefits prior to release. Improved medical reporting is increasing approval rates, enabling offenders to begin receiving benefits immediately upon release (Council on Homelessness 2005).

Georgia's "chronically homeless" population is linked with supportive housing before they are released from a facility-housing that is affordable and linked to services. The continuum of care includes new policies for discharge planning from public institutions that connect individuals with housing and services, and builds infrastructure that will eliminate the threat of homelessness and provide for adequate income and available services (Interagency Council on Homelessness 2004).

On April 13, 2004, Kentucky Governor Ernie Fletcher signed into law HB 376, the Homeless Prevention Pilot Project, which states: "...discharge to an emergency shelter is not appropriate," and bars discharges from foster care, mental health hospitals, and corrections into homelessness. Discharge planning is required that includes housing placement and links to other resources to achieve successful reentry into the community (Interagency Council on Homelessness 2004).

In Maryland, the "wraparound" model of service provision is being used to implement discharge plans for consumers leaving both public and private institutions. Seamless delivery of services is provided, such as psychiatric treatment within the community, medication management, transportation, life skills training, and other supports (SAMHSA 2003).

In January 2000, Massachusetts established a Working Group on Discharge Planning, which focused on the problems associated with releasing people into homelessness. Now needs assessments are conducted with people being discharged from correctional facilities. A "triage team" of service workers who can help plan for post-release needs is assembled; workshops and a re-integration program for 
substance abusers are offered to inmates to involve them in planning for release. Collaborations between the Department of Public Health and the Department of Mental Health provide specialized discharge planning services, and contracts for services with community-based service providers are in place for ex-offenders. Feedback is provided to discharge planners regarding the success and appropriateness of their efforts (Community Shelter Board 2002). Also, the Massachusetts Housing and Shelter Alliance (MHSA) helps agencies-mental health, public health, corrections, youth services, social services, county corrections, and for-profit managed care vendors - to explore homelessness prevention through discharge planning, to prepare people in institutions to return to the community, and to link them to housing and services (Mangano and Hombs 2002).

New Mexico has established adolescent transition groups to support youth with multiple vulnerabilities who are transitioning from state and local child welfare, juvenile justice, foster care, education, and mental health agencies. Discharge planning arranges for monthly half-day meetings with professionals, family members, and youth. These meetings are used to present the individual needs of youth, and to discuss possible solutions (National Alliance to End Homelessness 2006).

Since 1997, New York has funded a discharge case management team that works exclusively with individuals with mental illnesses returning to the community from state prisons. Case managers provide day of release contact, reach-in visits prior to release in selected cases, engagement of community housing and treatment providers, participation in and coordination of video case conferencing with community providers prior to an individual's release, and coordination with the Division of Parole and assigned parole officers. A Medication Grant Program provides a pharmacy benefits card to paroled individuals with mental illness (New York Department of Health \& Mental Hygiene 2006).

The Ohio Community-Oriented Reentry (CORE) Project targets adult offenders returning to Ohio's largest urban areas. Through CORE, the Department of Rehabilitation and Corrections partners with various service agencies through good discharge planning to address the challenges of recidivism, substance abuse, and physical and mental issues and to support education, workforce participation, housing, family re-unification, faith-based issues, and mentoring as part of the implementation of an individual offender's discharge plan (Community Shelter Board 2002).

In Utah the Housing First approach is used to prevent homelessness whenever possible, and to provide permanent supportive housing that makes it sustainable for those who are homeless. The State's 10-year plan focuses on effective discharge planning from public institutions and providing adequate services that promote housing stability and self-sufficiency (Utah Department of Community and Economic Development 2004).

The Virginia Office for Protection and Advocacy prepared a consumers' guide to discharge planning (2002). This document encourages consumers to work with their treatment teams to develop a good discharge plan, and outlines what the plan might include. 


\section{The Future of Discharge Planning}

Progress in discharge planning is taking place at a number of levels.

\section{Standardizing of Practice}

As states, counties, and cities implement their 10-year plans to end chronic homelessness, discharge planning is becoming more standardized, improving dayto-day practice. Screening instruments to routinize and enhance discharge planning constitute a promising practice deserving additional study and widespread use. Increased application of technology, featuring compatible data systems, makes the discharge planning process easier.

Given further empirical research about good practices in discharge planning such as those identified here, it is likely that certain methods for discharge planning will emerge as evidence-based practices for preventing homelessness. Such research validation can help increase the level of evidence for discharge planning and promote its implementation.

\section{Overarching Policies}

Policies that support discharge planning also are becoming more prevalent at state and local levels. A single entity often oversees the discharge planning policy, and develops relationships with other organizations, coordinates planning activities, and ensures fair distribution of available funds. The policy mobilizes systems integration processes among homeless, criminal justice, mental health, and substance abuse treatment systems (Thompson 2005). For instance, the Working Group on Discharge Planning in the Commonwealth of Massachusetts, in conjunction with the Working Group on Housing and Retention, convened relevant state agencies and developed a set of common policies and procedures for discharge planning in correctional facilities and human services agencies (Commonwealth of Massachusetts 2002; Thompson 2005).

\section{Partnerships}

Partnerships are essential to building a system for continuity of care, in which discharge planning can function effectively. Partnerships may include representatives from correctional facilities, parole/probation, law enforcement, the judiciary, social and human service agencies, nonprofit community support organizations, community providers, local foundations, advocates, the media, and others. However, determining who will be involved in discharge planning partnerships is only the first step. To establish effective partnerships and collaborations, partners must agree on how decisions are made, what procedures and practices are needed, and who is responsible for what part of the process (Thompson 2005).

Exemplary discharge planning includes a continuum of collaboration, ranging from shared information and memoranda of understanding to blended staff and joint financial agreements among agencies with demonstrated expertise. It features 
partnerships among all entities that can facilitate an individual's re-entry into the community and frequently involves agencies or institutions that have historically had competitive or adversarial relationships (SAMHSA 1997).

\section{Consumer Involvement}

During a brainstorming session on discharge planning held in Los Angeles in May 2006, a consumer suggested that mental health consumers who have exhibited stability in housing and treatment plans might be recruited to serve as coordinators and/or peer counselors on discharge planning teams. Consumers provide a unique perspective to the planning process, bringing their lived experiences to the task of identifying critical needs and facilitating the recovery process.

\section{Evaluation and Research}

Further progress in discharge planning will be aided by making resources available for evaluating the quality and impact of individual systems, and by promoting more rigorous empirical research. System planners, service program staff and program funders, as well as discharge planning personnel themselves, will benefit by knowing which activities have been successful in preventing homelessness and promoting recovery and community re-integration. A Management Information Systems (MIS) can be used to track clients and record types and costs of services, and can aid in making management decisions and evaluating discharge planning activities. In Rhode Island, for example, referrals and contacts for Fellowship Community Reintegration Services (CRS) are tracked on an online database by CRS discharge planners. Outcomes of services provided may also be tracked by state departments of mental health or by substance abuse and/or homeless agencies (see www.fellowshiphr.org/rhodeisland.asp for information).

Enhanced by such developments as these, discharge planning often provides a "strategic intercept" by addressing living arrangements, social supports, financial supports, and health and mental health issues; it may include provisions for accessing entitlements, obtaining employment, and receiving life skills training (Wells and Lezak 2004). However, discharge planning is not all the actual services involved in intervening in any of those areas, though it may involve some aspects of getting services provided. It is not developing community housing and services, and it is not community-based programs offered to people after they are discharged, such as ACT, CTI or Housing First.

As already emphasized, these critical elements of the continuum of care must be in place in order for discharge planning to be effective. Advocacy to promote change in service systems for people at risk for homelessness (see Wells 2005, Principles of Effective Transition Planning. Unpublished paper, for example) will be needed to realize the potential of discharge planning as part of the puzzle in preventing homelessness.

To make discharge planning processes work better, so that they help consumers find stable housing and other needed services when they leave an institutional setting, all parts of the service system must be improved. Individual service workers 
need to learn more about how to do skillful discharge planning. Consumers and family members need to learn what their roles may be. And policymakers can play a part in larger-scale systems change on this subject.

Acknowledgments Preparation of this paper was supported by the Knowledge Application Program Project, Center for Mental Health Services Task Order 270-03-6005. The authors acknowledge with gratitude the input provided by Dr. Deborah Stone, Center for Mental Health Services; and Dr. Mary Anne Myers, Westat. Useful input also was provided by William Compton, Project Return, Los Angeles; and Dr. Timothy Kuehnel, research psychologist.

\section{References}

American Association of Community Psychiatrists. (2001). AACP continuity of care guidelines: Best practices for managing transitions between levels of care. Pittsburgh, PA: American Association of Community Psychiatrists.

Backer, T. E., \& Howard, E. A. (1997). Integrated service programs for women with multiple vulnerabilities. Culver City, CA: PROTOTYPES Systems Change Center.

Backer, T. E., \& Howard, E. A. (in press). Cognitive impairments and prevention of homelessness: Research and practice review. Journal of Primary Prevention.

Bazelon Center for Mental Health Law. (2004). Discharge planning for inmates being released from jail or prison. Washington, DC: Bazelon Center for Mental Health Law.

Bazelon Center for Mental Health Law. (2006). Best practices: Access to benefits for prisoners with mental illness. Washington, DC: Bazelon Center for Mental Health Law.

Belcher, J. R. (1991). Moving into homelessness after psychiatric hospitalization. Journal of Social Work Research, 14, 63-77.

Burley, C. (2003). Victory for inmates with mental illnesses. Washington, DC: Bazelon Center for Mental Health Law.

Burns, P., Flaming, D., \& Haydamick, B. (2003). Homeless in LA: A working paper for the 10-year plan to end homelessness in Los Angeles County. Los Angeles: Economic Roundtable.

Caton, C. L. M. (1981). The new chronic patient and the system of community care. Hospital Community Psychiatry, 32, 475-4781.

Christ, W., Clarkin, J., \& Hull, J. (1994). A high-risk screen for psychiatric discharge planning. Health and Social Work, 19(4), 261-270.

City of Berkeley, Housing Department. (1996). Berkeley Homeless Continuum of Care Plan, III: Policy priority elements, A. Eviction prevention. Berkeley, CA: City of Berkeley, Housing Department. Retrieved February 20, 2007, from www.ci.berkeley.ca.us/housing.

Colorado Department of Human Services, Discharge Planning Committee (2006). Report of recent council accomplishments based upon council strategic plan. Denver, CO: Colorado Department of Human Services, Discharge Planning Committee.

Commonwealth of Massachusetts. (2002). Discharge planning specifications for requests for responses. Boston, MA: Commonwealth of Massachusetts.

Community Shelter Board. (2002). Preventing homelessness: Discharge planning from corrections facilities. Columbus, $\mathrm{OH}$ : Community Shelter Board.

Council on Homelessness. (2005). Council on Homelessness: 2005 report. Tallahassee, FL: Council on Homelessness.

Culhane, D. P., Metraux, S., \& Hadley, T. (2002). Public service reductions associated with placement of homeless persons with severe mental illness in supportive housing. Housing Policy Debate, 13(1), $107-163$.

Fernando, M. L. D., Velamoor, V. R., Cooper, A. J., \& Cernovsky, Z. (1990). Some factors relating to satisfactory post-discharge community maintenance of chronic psychotic patients. Canadian Journal of Psychiatry, 35, 71-73.

Florida Department of Children and Families. (2006). Chapter 5: Diagnoses, individualized treatment planning, medications \& discharge. In Florida Department of Children and Families (Eds.), Guardian advocate training and resource manual (pp. 11-13). Tallahassee, FL: Florida Department of Children and Families. 
Gantt, A., Cohen, N. L., \& Sainz, A. (1999). Impediments to the discharge planning effort for psychiatric inpatients. Social Work in Health Care: The Journal of Health Care Social Work, 29(1), 1-14.

Hogarty, G. (1972). Discharge readiness inventory. Archives of General Psychiatry, 26, 419-425.

Interagency Council on the Homeless (ICH). (1994). Priority home! The federal plan to break the cycle of homelessness [HUD-1454-CPD]. Washington, DC: Interagency Council on the Homeless.

Interagency Council on Homelessness. (2004). Improving discharge planning outcomes: Kentucky passes homelessness prevention legislation. Retrieved February 19, 2007, from http://www.ich.gov/ innovations.

Joint Commission on Accreditation of Healthcare Organizations. (2003). Behavioral health care standards crosswalk. Chicago: Joint Commission on Accreditation of Healthcare Organizations.

Kadushin, G., \& Kulys, R. (1993). Discharge planning revisited: What do social workers actually do in discharge planning? Social Work, 38, 713-726.

Kiser, L. J., Lefkovitz, P. M., Kennedy, L. L., Knight, M. A., Moran, M., \& Zimmer, C. J. (1999). The continuum of behavioral healthcare services: A position paper from The Association for Ambulatory Behavioral Healthcare. Retrieved February 19, 2007, from www.aabh.org/public/detailpgs/continuum.html.

Lamport, J. (2005, July). Homeless programs that are working, so far. Gotham Gazette: New York City News and Policy, 10(1482). Retrieved March 12, 2007, from http://gothamgazette.com/article// 20050715/10/1482.

Lehman, A. F., Dixon, L., Hoch, J. S., Deforge, B., Kernan, E., \& Frank, R. (1999). Cost-effectiveness of assertive community treatment for homeless persons with severe mental illness. British Journal of Psychiatry, 174, 346-352.

Lurie, A., Pinsky, S., \& Tuzman, L. (1981). Training social workers for discharge planning. Health and Social Work, 6(4), 12-18.

Mangano, P. F., \& Hombs, M. E. (2002). Introduction and overview - preventing homelessness: Tools and resources for discharge planning. Boston, MA: Massachusetts Housing and Shelter Alliance.

Minkoff, K. (2001). Behavioral health recovery management service planning guidelines: Co-occurring psychiatric and substance disorders. Chicago, IL: Illinois Department of Human Services, Office of Alcoholism and Substance Abuse.

Moran, G., Semansky, R., Quinn, E., Noftsinger, R., \& Koenig, T. (2005). Evaluability assessment of discharge planning and the prevention of homelessness final report. Washington, DC: Office of the Assistant Secretary for Planning and Evaluation, Department of Health and Human Services.

National Alliance to End Homelessness. (2006). New Mexico adolescent transition groups. Retrieved February 19, 2007, from http://www.endhomelessness.org/content/article/detail/1122/.

New York City Department of Health and Mental Hygiene. (2006). Health care access and improvement. Retrieved February 19, 2007, from www.nyc.gov/html/doh/html/hca/forensicsrv.shtml.

Osher, F., Steadman, H. J., \& Barr, H. (2002). A best practice approach to community re-entry from jails for inmates with co-occurring disorders: The APIC Model. Delmar, NY: The National GAINS Center.

Parks, G. A., \& Marlatt, A. (2000). Relapse prevention therapy: A cognitive-behavioral approach. The National Psychologist, 9(5), 3.

Rock, B. (1987). Beyond discharge planning. Hospital and Community Psychiatry, 38, 529-530.

Sosin, M. R., \& Grossman, S. (1991). The mental health system and the etiology of homelessness: A comparison study. Journal of Community Psychology, 19, 337-350.

Rosen, J., \& Perret, Y. (2005). Stepping stones to recovery: A case manager's manual for assisting adults who are homeless with Social Security Disability and Supplemental Security Income applications [DHHS Pub. No. SMA 05-4051]. Rockville, MD: Center for Mental Health Services, Substance Abuse and Mental Health Services Administration.

Substance Abuse and Mental Health Services Administration, Center for Mental Health Services. (1997). Exemplary practices in discharge planning: Report and recommendations of the working conference June 1997. Rockville, MD: Substance Abuse and Mental Health Services Administration, Center for Mental Health Services.

Substance Abuse and Mental Health Services Administration, Center for Mental Health Services. (2003). Blueprint for change: Ending chronic homelessness for persons with serious mental illnesses and co-occurring substance use disorders [DHHS Pub. No. SMA-04-3870]. Rockville, MD: Substance Abuse and Mental Health Services Administration, Center for Mental Health Services.

Thompson, M. (2005). Memorandum to the Regional Steering Committee on Homelessness and Housing, State of California, Re: Discharge from State corrections: Partnering ctate and local agencies to 
create effective discharge planning policy. Retrieved February 20, 2007, from www.homebaseccc.org.

U.S. Department of Housing and Urban Development, Office of Community Planning and Development. (2003). Customized bibliography: Discharge planning from publicly funded institutions. Washington, DC: U.S. Department of Housing and Urban Development, Office of Community Planning and Development.

Utah Department of Community and Economic Development. (2004). Utah's ten year business plan to end chronic homelessness. Ogden, UT: Utah Department of Community and Economic Development.

Virginia Office for Protection and Advocacy. (2002). Ready for discharge: A mental health consumer's guide to discharge planning, rights and sources of help in the community, and self-advocacy. Richmond, VA: Virginia Office for Protection and Advocacy.

Wells, S. M., \& Lezak, A. (2004). Research and review: Preliminary report on local, state and national efforts to prevent and end homelessness. Raleigh, NC: ADL Consulting in partnership with the City of Raleigh, Wake County, Wake Continuum of Care and Triangle United Way.

Western Interstate Commission for Higher Education, WICHE Mental Health Program. (1998). Discharge planning. In Cultural competence standards in managed mental health care for four underserved/underrepresented racial/ethnic groups (pp. 17-18). Boulder, CO: Western Interstate Commission for Higher Education. 